\title{
Analysis of the Effect of Groundwater Exploitation on High-Speed Railway Pile-Slab Structure Subgrade
}

\author{
Hong Xiao*, Xiao Guo and Luwei Huang
}

Beijing Key Laboratory of Track Engineering, Beijing Jiaotong University, 100044, Beijing, P.R. China

\begin{abstract}
Land settlement produced by groundwater exploitation may cause larger deformation of the high-speed subgrade. To meet the settlement control requirements after construction of the high standard of high-speed railway subgrade, Pile-Slab composite foundation treatment technology keeps developing and applying in high-speed railway construction. However, the settlement deformation calculation theory of Pile-Slab composite foundation is not mature, in particular, the research for Pile-Slab composite foundation deformation caused by groundwater exploitation is seldom, which is far behind the requirements of engineering practice. To study the effect of exploiting groundwater near the highspeed railway on Pile-Slab composite foundation deformation, in this paper, we establish 3D fluid-solid coupling model using ABAQUS, analyze the effect of different groundwater exploiting quantities on high-speed railway subgrade when CFG piles are used to strengthen the foundation, and compare to the result with no CFG piles. The analysis shows that in the condition of pumping water, CFG Pile-Slab composite foundation has a significant effect on decreasing subgrade lateral deformation and settlement which are reduced by $70 \%$.
\end{abstract}

Keywords: 3D fluid-solid coupling model, CFG piles, groundwater exploitation, subgrade settlement.

\section{INTRODUCTION}

Over exploitation of groundwater is the main cause of land settlement. At present, land settlement in more than half of the provinces in China is caused by excess exploitation of groundwater, among them, more than fifty cities are faced with serious settlement, north china plain where Beijing is located has been the largest groundwater funnel area in the world [1]. China has the longest operation mileage and largest scale of construction of high-speed railway in the world and will build more lines according to $<$ Middle and Long-Term Railway Network Planning > (adjusted in 2008). High-speed railway ballastless track is so sensitive to foundation settlement deformation that large distortion will appear because of the land settlement, then, it will affect the forced deformation and service life of the ballestless track, affect the safe and steady operation of the train [2]. According to $<$ Regulation on the Administration of Railway Safety $>$ [3], in the range of $200 \mathrm{~m}$ outwards of lateral side of high-speed railway embankment slope toe, cutting slope top and bridge, it is forbidden to pump groundwater. Now, problems of subgrade settlement have been produced due to over exploitation of groundwater in some areas of China, for example, near to Tianjin DK119 DK123 of Jing-Hu highspeed railway, there exists larger subsidence areas, it has a big hidden trouble for running security. Via field survey, the settlement is closely related to over exploitation of groundwater from a power plant well [4].
High-speed railway underline engineering deformation is required to be controlled in a certain limit at home and abroad [5]. To satisfy the requirements of foundation strength, deformation and seismic behavior, especially for meeting the settlement control requirements after construction of the high standard of high-speed railway subgrade, Pile-Slab composite foundation treatment technology keeps developing and applying in high-speed railway construction $[6,7]$. Pile-Slab composite foundation technology has the characteristics of little settlement, wellcontrol uneven settlement, high strength, stability and good durability. However, because the technology of Pile-Slab composite foundation is complicated, the settlement deformation calculation theory of Pile-Slab composite foundation is not mature, in particular, the research for PileSlab composite foundation deformation caused by groundwater exploitation is seldom, which are far behind the requirements of engineering practice. Therefore, it is very necessary to carry out the study of the effect of groundwater exploitation on Pile-Slab structure subgrade [8-10].

In this paper, we establish 3D fluid-solid coupling model using ABAQUS, analyze the effect of different groundwater exploiting quantities on high-speed railway subgrade when CFG piles are used to strengthen the foundation, compare to the result with no CFG piles, and provide theory guidance for high-speed railway construction and operation maintenance.

\section{NUMERICAL ANALYSIS MODEL AND PARAMETERS}

To study the effect of exploiting groundwater on highspeed railway subgrade when $\mathrm{CFG}$ piles are used to 


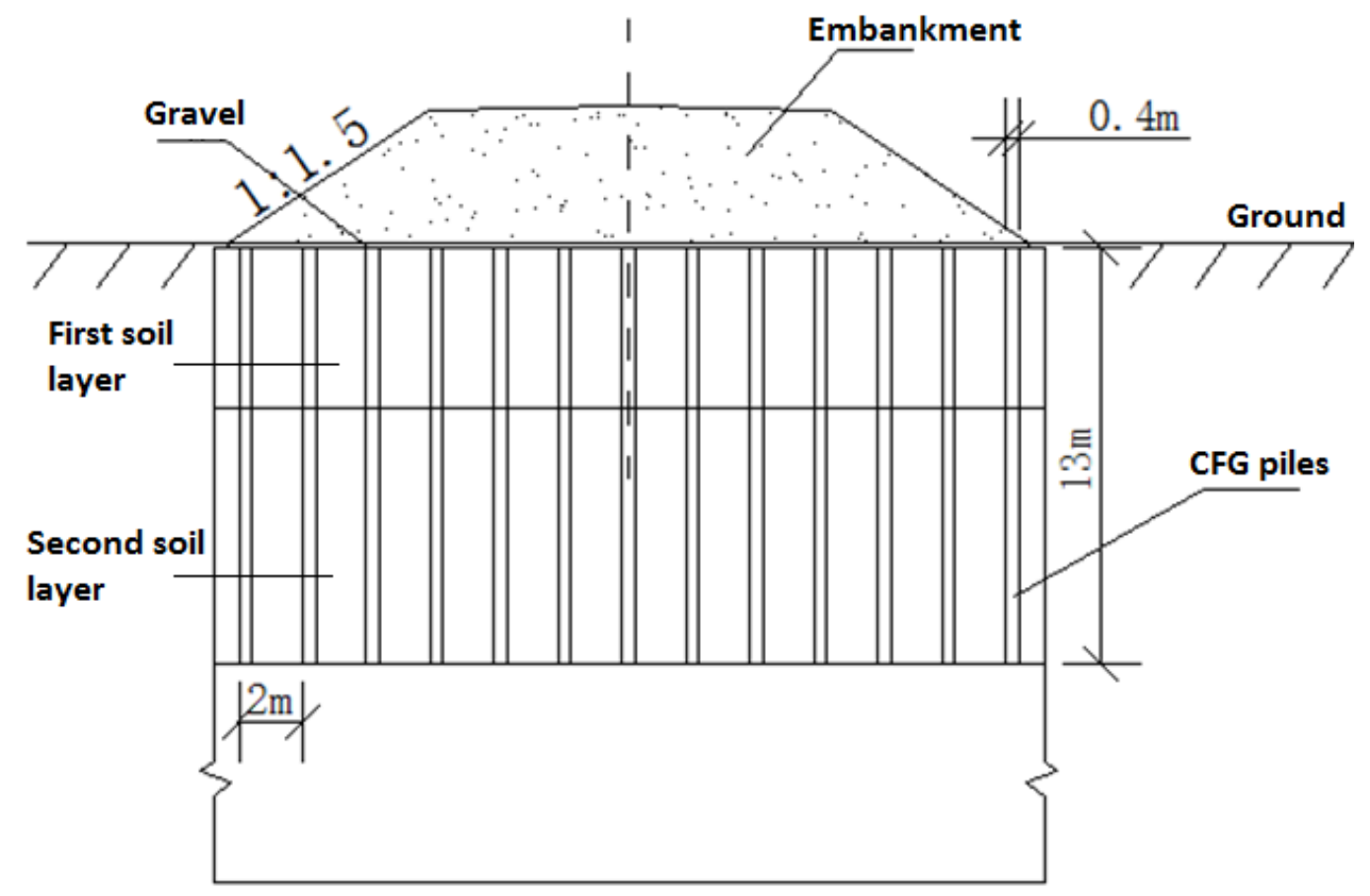

Fig. (1). Cross section of CFG piles reinforcement subgrade of fengyang test section in jing-hu high-speed railway.

strengthen the foundation, in this paper, we choose Fengyang test section CFG piles foundation of Jing-Hu high-speed railway as the study object to build finite element model. Fengyang test section in Jing-Hu high-speed railway is designed to lay ballestless track and CFG Pile-Slab composite foundation treatment technology is used to strengthen the foundation. The reinforcement section is 90 meters long, the pile diameter of CFG is 0.4 meters, pile length is 13 meters, the pile spacing is 2 meters, and section schematic diagram can be seen in Fig. (1).

According to investigated arrangement of four pumping wells near railway, the wells are linear paralleling to the railway from north to south, and the well spacing is 100 124 meters, only 60 meters latest to the railway. To simplify the model, we only consider a single pumping well which is 60 meters apart from the center line of subgrade. The pumping speed is at $500 \mathrm{~m}^{3} / \mathrm{d}, 750 \mathrm{~m}^{3} / \mathrm{d}$ and $1000 \mathrm{~m}^{3} / \mathrm{d}$. The model area is $100 \times 100 \mathrm{~m}^{2}$ and mainly includes embankment, formation, pumping well and CFG piles. The formation soil is simulated by C3D8RP elements, piles, gravel cushion, reinforced concrete slabs and subgrade are simulated by C3D8R elements. The piles need special treatment, that is, the cylinders should be transformed into square piles in equal sectional area.

In the model, the thickness of subgrade is 4.2 meters, the width of roadbed is 13.6 meters, the subgrade slope is $1: 1.5$; the thickness of formation soil is 28 meters which is divided into four layers, two of them are in strengthened areas which are 13 meters in total, and the first layer is 5 meters, the second layer is 8 meters. The thickness of substratum is 23 meters which is divided into two layers, the third layer is 5 meters, the forth layer is 10 meters. The pumping well diameter is 1.5 meters and the length is 13 meters. The groundwater level takes 5 meters below the earth's surface, and the pumping depth is through the whole aquifer stratum (the depth is $5 \sim 13 \mathrm{~m}$ ). Cross section of the model can be seen in Fig. (2).

Refer to laboratory test, field test and literatures, the calculation parameters of foundation soil layers, subgrade, gravel cushion, reinforced concrete slabs and CFG piles in certain conditions are shown in Table 1. The model schematic diagram of subgrade, formation, CFG Pile-Slab composite foundation is shown in Fig. (3).

\section{CALCULATION RESULTS}

According to CFG piles foundation reinforcement engineering example in Jing-Hu high-speed railway and pumping groundwater actual conditions near railway, 3D fluid-solid coupling model is established, and comparison for the calculation results can be seen in the figures.

\subsection{Subgrade Lateral Deformation}

From the above Fig. (4), we can see that, for using or not using CFG piles, subgrade lateral displacement along railway longitudinal length presents a upward convex morphology, that is, the subgrade section which the pumping well corresponds to has the largest lateral deformation, and the closer to the ends, the smaller the lateral deformation is. The largest displacements at subgrade center which the pumping well corresponds to in different conditions can be seen in Fig. (5).

It can be seen from Fig. (5) that, with three different pumping yields, the effect of CFG piles on subgrade lateral displacement is obvious. Comparing using CFG piles to nonpiles, we can find that the lateral displacement presents a significant decline by $70 \%$, for example, in the condition of pumping yield $750 \mathrm{~m}^{3} / \mathrm{d}$, the largest lateral displacement is 


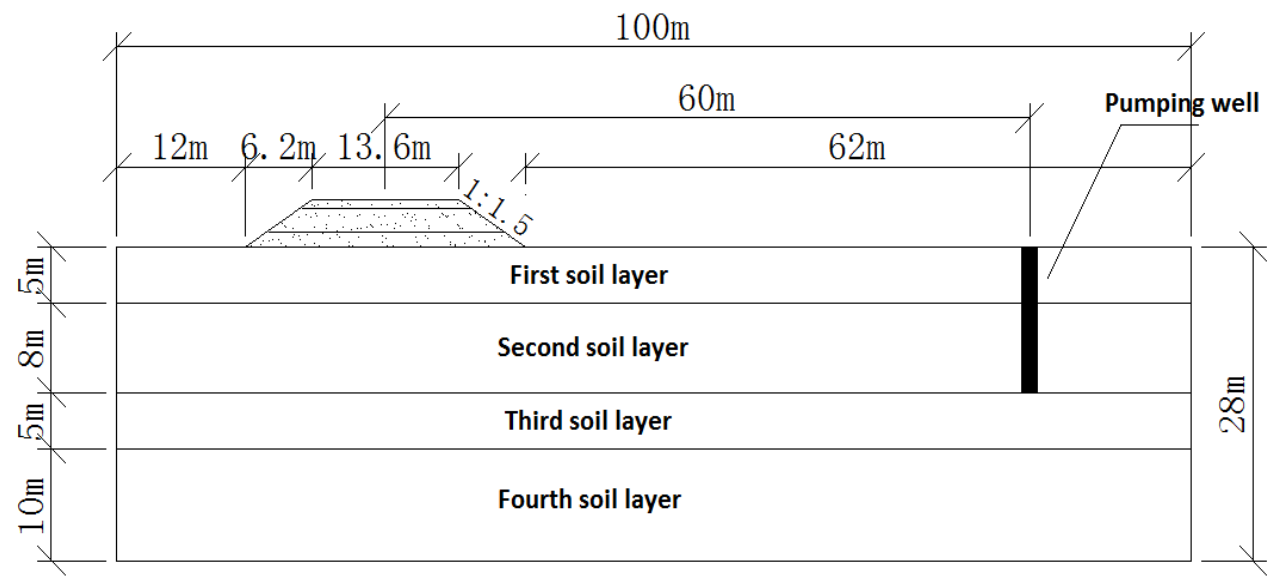

Fig. (2). Cross section of the model.

Table 1. Parameters of different soil layers.

\begin{tabular}{|c|c|c|c|c|c|c|}
\hline Layer Name & Thickness (m) & Density $\rho\left(\mathrm{kg} / \mathrm{m}^{3}\right)$ & Void Ratio e & Young Modulus E (Pa) & Poisson Ratio $\mu$ & Permeability Coefficient (m/s) \\
\hline Subgrade surface layer & 0.4 & 1950 & I & $1.5 \mathrm{E} 8$ & 0.25 & I \\
\hline Subgrade body & 1.5 & 1700 & / & $5.0 \mathrm{E} 7$ & 0.25 & / \\
\hline First soil layer & 5 & 1910 & 0.82 & $1.8 \mathrm{E} 7$ & 0.30 & $9.6 \mathrm{E}-8$ \\
\hline Third soil layer & 5 & 2100 & 0.1 & $1.5 \mathrm{E} 8$ & 0.15 & $1.0 \mathrm{E}-9$ \\
\hline Fourth soil layer & 10 & 2310 & 0.1 & $5.0 \mathrm{E} 8$ & 0.15 & $1.0 \mathrm{E}-9$ \\
\hline Gravel cushion & 0.2 & 2100 & l & $1.2 \mathrm{E} 8$ & 0.15 & / \\
\hline Reinforced concrete slab & 0.5 & 2400 & l & $3.0 \mathrm{E} 10$ & 0.10 & l \\
\hline
\end{tabular}

$11.15 \mathrm{~mm}$ with non-piles while $3.39 \mathrm{~mm}$ with CFG piles, decreased by $69.9 \%$. So, applying CFG piles to strengthen the foundation for controlling lateral displacement of the subgrade in the condition of pumping groundwater can acquire a remarkable effect.

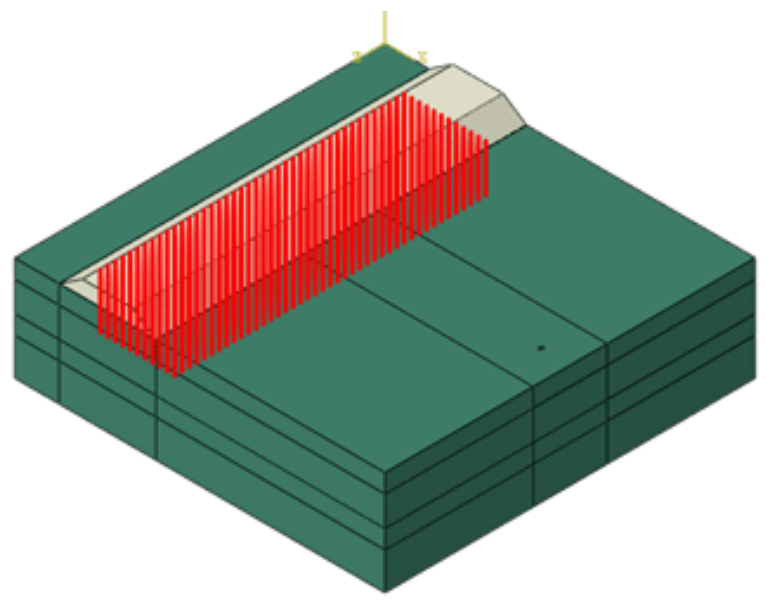

Fig. (3). The model schematic diagram of subgrade, formation, CFG Pile-Slab composite foundation.

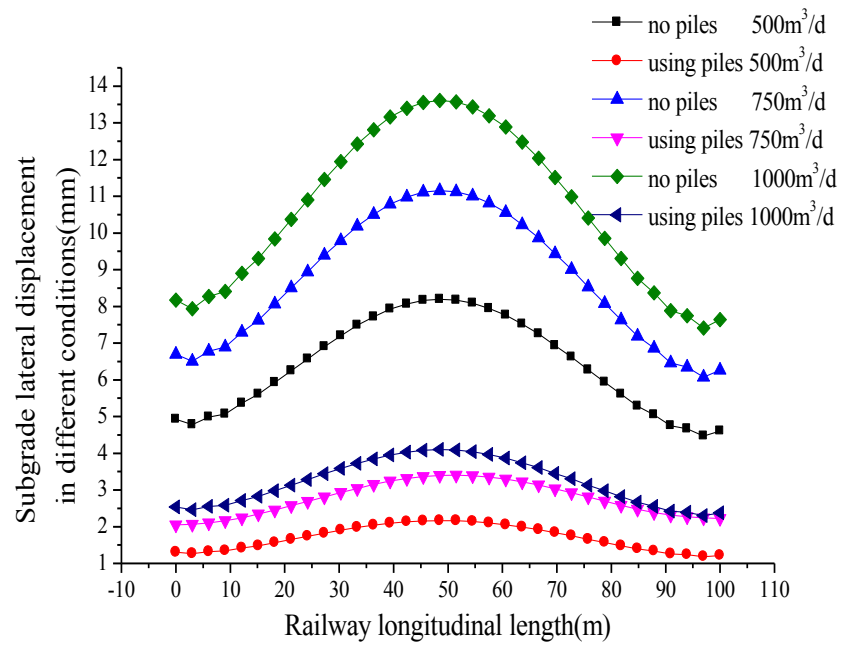

Fig. (4). Subgrade lateral displacement along railway longitudinal length in different conditions.

\subsection{Subgrade Settlement}

It can be seen from the above Fig. (6) that, for using or not using $\mathrm{CFG}$ piles, subgrade settlement along railway 
longitudinal length shows a concave shape, that is, the subgrade section which the pumping well corresponds to has the largest settlement, and the closer to the ends, the smaller the settlement is. The largest settlements at subgrade center which the pumping well corresponds to in different conditions can be seen in Fig. (7).

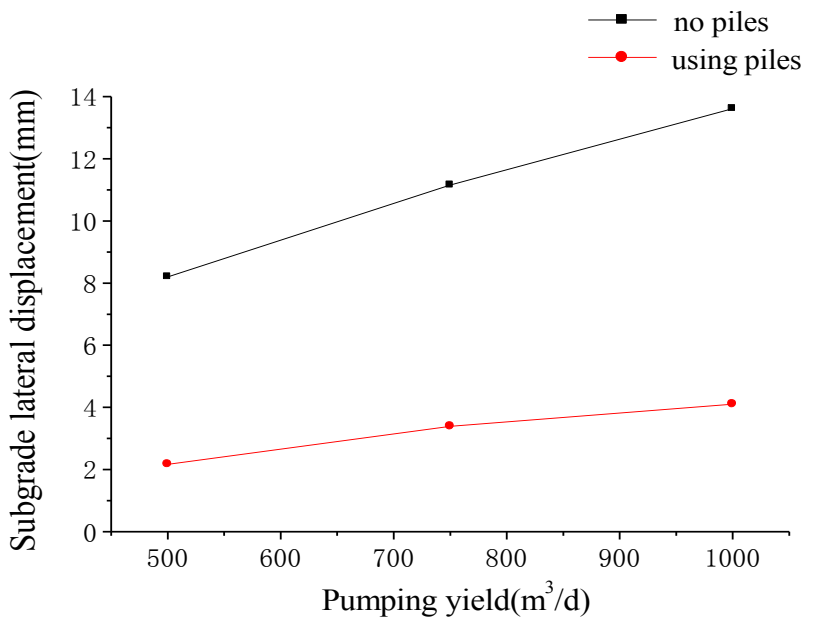

Fig. (5). Subgrade largest lateral displacement in different conditions.

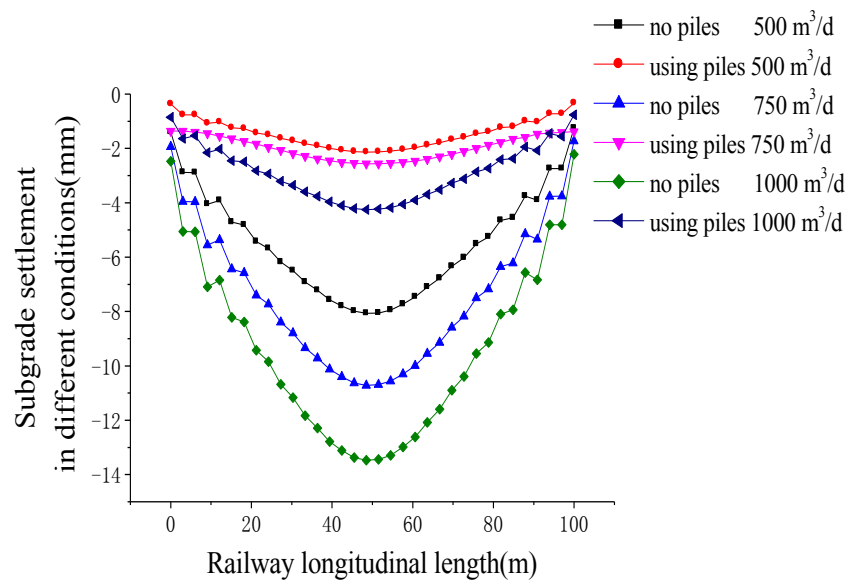

Fig. (6). Subgrade settlement along railway longitudinal length in different conditions.

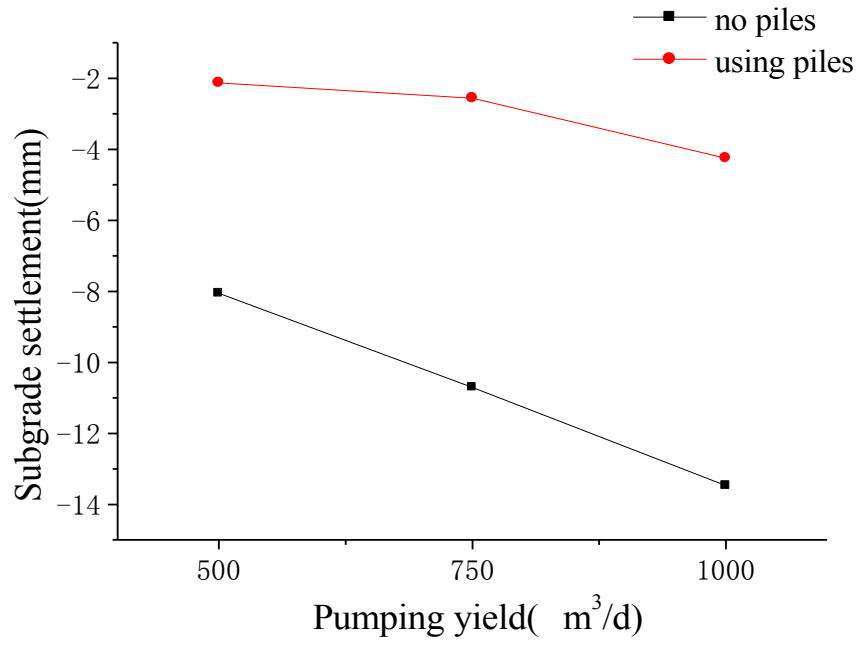

Fig. (7). Subgrade largest lateral displacement in different conditions.

\section{CONCLUSION}

In this paper, by using ABAQUS, we study the effect of groundwater exploitation on the Pile-Slab structure subgrade, establish 3D fluid-solid coupling model, and compare the high-speed railway subgrade deformations in two conditions: using CFG piles and non-piles. We can get the following conclusions:

(1) With three different pumping yields, CFG pile has obvious function in reducing the lateral deformation of subgrade. Compared with non-piles, the lateral displacement has a larger decline by approximately $70 \%$ when we use CFG piles to consolidate subgrade. For example, in the condition of pumping yield $750 \mathrm{~m}^{3} / \mathrm{d}$, the largest lateral displacement is $11.15 \mathrm{~mm}$ with non-piles while $3.39 \mathrm{~mm}$ with $\mathrm{CFG}$ piles, decreased by $69.9 \%$.

(2) With three different pumping yields, CFG pile also plays a significant role in reducing subgrade settlement. The settlement, using $\mathrm{CFG}$ piles to strengthen the subgrade, has a larger decline by approximately $75 \%$ compared to that with non-piles, which is coincidence with the law of the lateral displacement. For example, in the case of pumping yield $750 \mathrm{~m}^{3} / \mathrm{d}$, the largest settlement is $10.71 \mathrm{~mm}$ with non-pile, and it changes to $2.56 \mathrm{~mm}$ when we use CFG piles, decreased by $76.1 \%$.

(3) In view of the significant effect of Pile-Slab composite foundation on controlling subgrade deformation of high-speed railway caused by groundwater exploitation, it is suggested that when we build high-speed railway in regional subsidence areas, it should be combined with engineering practice, applying CFG Pile-Slab composite foundation rationally, so as to meet the requirements of controlling subgrade post-construction settlement, reduce the influence on ballestless track and ensure train operation safety.

\section{CONFLICT OF INTEREST}

The authors confirm that this article content has no conflict of interest.

\section{ACKNOWLEDGEMENTS}

This work was financially supported by Science and technology research and development program of China Railway Corporation (2013G004-B-2), Beijing Nova Program (Z12111000250000) and National Natural Science Foundation of China Financing Projects (No.50908013).

\section{REFERENCES}

G. H. Li, Z. L. Xu, and S. L. Sun, "The influence of surface subsidence on construction of high-speed railway in North China plain and its countermeasures," Journal of Railway Engineering Society, vol. 24, pp. 7-12, 2007.

Q. C. He, W. B. Liu, and Z. M. Li, "Land subsidence survey and monitoring in the North China plain," Geological Journal of China Universities, vol. 12, pp.195-209, 2006.

"Regulation on the Administration of Railway Safety," The State Council of the people's Republic of China, 2013. 
[4] G. X. Liu, and X. L. Ding, "Detecting of surface deformation in coastlands by DInSAR: accuracy and applicability analysis," Bulletin of Surveying and Mapping, vol. 6, pp. 9-13, 2006.

[5] Sunaga and Makoto, "Vibration behavior of roadbed on softgrounds under trainload;" Quartly Report of RTRI, vol. 31, pp. 29-35, 1990.

[6] W. B. Tu, and Y. F. Li, "Influence Analysis of Pile-slab Composite Foundation on the Settlement of High-speed Railway," Subgrade Engineering, vol. 3, pp. 172-175, 2011.

[7] J. S. Zhang, "Application of subsoil reinforcing technique using pile-slab structure for Beijing-Tianjin intercity railway," Railway Engineering, vol. 1, pp. 156-158, 2008.
[8] M. J. Ding, "Numerical simulation on the post-construction settlement of CFG pile-slab composite foundation in high-speed railway," China Railway Science, vol. 29, pp. 1-6, 2008.

[9] X. H. Li, Y. Yue, and Y. P. Shen, "Analyses of effects of application of CFG pile in Beijing section of urban mass transit between beijing and tianjin," Journal of Railway Engineering Society, vol. 1, pp. 117-119, 2007.

[10] B. L. Wang, and Q. M. Gong, "Numerical analysis about effect of design parameters of CFG pile composite foundation on its settlement," Railway Engineering, vol. 7, pp. 24-26, 2007. 